\title{
Microelectrode recording findings within the tractography-defined ventral intermediate nucleus
}

\author{
Nicolas Kon Kam King, FRCSEd(SN), PhD, ${ }^{1,2}$ Vibhor Krishna, MD, ${ }^{1,3}$ Diellor Basha, BS, ${ }^{5}$ \\ Gavin Elias, BA, ${ }^{1}$ Francesco Sammartino, MD, ${ }^{1}$ Mojgan Hodaie, MD, ${ }^{1,4}$ Andres M. Lozano, MD, PhD, ${ }^{1}$ \\ and William D. Hutchison, $\mathrm{PhD}^{5}$
}

\begin{abstract}
'Division of Neurosurgery, Department of Surgery, University of Toronto; ${ }^{4}$ Division of Brain Imaging, Behaviour Systems Neuroscience, Toronto Western Research Institute; ${ }^{5}$ Department of Physiology, Toronto Western Hospital, University of Toronto, Ontario, Canada; ${ }^{2}$ Department of Neurosurgery, National Neuroscience Institute, Singapore; and ${ }^{3}$ Center for Neuromodulation, Department of Neurosurgery, The Ohio State University, Columbus, Ohio
\end{abstract}

OBJECTIVE The ventral intermediate nucleus (VIM) of the thalamus is not visible on structural MRI. Therefore, direct VIM targeting methods for stereotactic tremor surgery are desirable. The authors previously described a direct targeting method for visualizing the VIM and its structural connectivity using deterministic tractography. In this combined electrophysiology and imaging study, the authors investigated the electrophysiology within this tractography-defined VIM (T-VIM).

METHODS Thalamic neurons were classified based on their relative location to the T-VIM: dorsal, within, and ventral to the T-VIM. The authors identified the movement-responsive cells (kinesthetic and tremor cells), performed spike analysis (firing rate and burst index), and local field potential analysis (area under the curve for $13-30 \mathrm{~Hz}$ ). Tremor efficacy in response to microstimulation along the electrode trajectory was also assessed in relation to the T-VIM.

RESULTS Seventy-three cells from a total of 9 microelectrode tracks were included for this analysis. Movement-responsive cells ( 20 kinesthetic cells and 26 tremor cells) were identified throughout the electrode trajectories. The mean firing rate and burst index of cells $(n=27)$ within the T-VIM are $18.8 \pm 9.8 \mathrm{~Hz}$ and $4.5 \pm 5.4$, respectively. Significant local field potential beta power was identified within the T-VIM (area under the curve for $13-30 \mathrm{~Hz}=6.6 \pm 7.7$ ) with a trend toward higher beta power in the dorsal T-VIM. The most significant reduction in tremor was also observed in the dorsal T-VIM.

CONCLUSIONS The electrophysiological findings within the VIM thalamus defined by tractography, or T-VIM, correspond with the known microelectrode recording characteristics of the VIM in patients with tremor.

https://thejns.org/doi/abs/10.3171/2016.3.JNS151992

KEY WORDS microelectrode recording; deterministic tractography; ventralis intermedius nucleus tractography; tractography-based targeting; functional neurosurgery

$\mathrm{T}$ HERE is a significant interest in devising direct targeting methods for the thalamic ventral intermediate nucleus (VIM) for tremor surgery. $12,25,26$ These investigations have in part been driven by 2 major developments: the identification of cerebellar input to the VIM as a therapeutic target ${ }^{26,50}$ and the introduction of noninvasive procedures (Gamma Knife and MRI-guided focused ultrasound), which dispense with any physiological exploration of the ventral thalamus. ${ }^{15,34,56}$ We recently described a method for tractography-based VIM (T-VIM) targeting. ${ }^{37}$ This method involves a step-wise localization of the VIM by checking the anatomical accuracy at each step. First, the borders of the VIM are visualized by tracking the pyramidal tract (PT) and medial lemniscus (ML) (these tracts define the VIM's lateral and posterior borders, respectively). A VIM region of interest (ROI), similar in dimensions to the human VIM, is then created $3 \mathrm{~mm}$ away from both the PT and ML. Finally, the structural connectivity of the VIM with the cerebellum (via the dentatorubrothalamic tract (DRT), which terminates in the $\mathrm{VIM}^{4}$ ) and motor cortex (primary motor and premotor cortex) is confirmed. The reproducibility and clinical application of this methodology was described previously. In this paper we analyzed the electrophysiological findings rela-

ABBREVIATIONS CRST = Clinical Rating Scale for Tremor; DBS = deep brain stimulation; DRT = dentatorubrothalamic tract; $\mathrm{DTI}=$ diffusion tensor imaging; ISI = interspike interval; LFP = local field potential; $M E R=$ microelectrode recording; $M L$ = medial lemniscus; $P T$ = pyramidal tract; $R O I$ = region of interest; $T$-VIM = tractographybased VIM; VIM = ventral intermediate nucleus.

SUBMITTED August 24, 2015. ACCEPTED March 31, 2016.

INCLUDE WHEN CITING Published online July 22, 2016; DOI: 10.3171/2016.3.JNS151992. 
tive to T-VIM imaging, within the same patient cohort, to correlate the 2 methods of target localization and further evaluate the merit of imaging findings.

The VIM has a distinct electrophysiological signature in humans. ${ }^{20}$ Microelectrode recording (MER) studies have shown that VIM neurons fire within a frequency range of 10 to $15 \mathrm{~Hz},{ }^{31}$ exhibit irregular firing patterns, ${ }^{29}$ and are often responsive to active movement-responsive ("voluntary" cells), joint movement/pressure-sensitive ("kinesthetic" cells), or active movement- and joint movement/pressure-responsive ("combined" cells). ${ }^{30,32}$ These cells include those that have periodic oscillations in their firing rate at tremor frequency $(3-8 \mathrm{~Hz})$, which is frequently coherent with limb or jaw tremor measured using electromyography or an accelerometer. ${ }^{21,33}$ More recently, the local field potential (LFP) within the VIM has been found to have prominent beta oscillations $(13-30 \mathrm{~Hz})^{6}$ which appears to attenuate when tremor frequency oscillations appear, followed by tremor in the limbs. We hypothesized that these distinct electrophysiological features of the VIM should delineate the borders of this nucleus and therefore coregister with the borders determined by the T-VIM. We studied tremor patients (those with essential tremor and those with tremor-dominant Parkinson's disease) who underwent preoperative diffusion tensor imaging (DTI) and MER-guided VIM procedures (either thalamotomy or deep brain stimulation [DBS]). The trajectory of the dual recording electrode was analyzed in relation to T-VIM and the findings were categorized into 3 locations-dorsal to, within, and ventral to the T-VIM. We compared the spike pattern (firing rate, burst index), LFP (spectral analysis and area under the curve for the beta oscillations), and tremor efficacy at these 3 different locations.

\section{Methods}

The methods used in this study were approved by the University Health Network Research Ethics Board.

\section{Patient Population}

Combined tractography and electrophysiology was performed in 6 patients undergoing functional stereotactic procedures for disabling tremor between November 2014 and January 2015. Three patients had essential tremor, and 3 had tremor-dominant Parkinson's disease. Physiological exploration of the VIM of the thalamus was performed in all patients using the MER-guided technique described elsewhere. ${ }^{30}$

\section{Imaging Protocol}

Diffusion tensor imaging (DTI) was performed using a 3-T magnet (GE Signa). The sequence included 60 directions of diffusion gradients $\left(b=1000 \mathrm{sec} / \mathrm{mm}^{2} ; 0.94 \times\right.$ $0.94 \times 3 \mathrm{~mm}$ voxel size; TE $86.6 \mathrm{msec}$; TR $12,000 \mathrm{msec}$; matrix $128 \times 128$ ). 3D fast spoiled gradient echo axial T1weighted images were also acquired (voxel size $0.85 \times$ $0.85 \times 1 \mathrm{~mm}$, matrix $256 \times 256$, FOV $220 \mathrm{~mm}$, TE $5 \mathrm{msec}$, TR $12 \mathrm{msec}$, TI $300 \mathrm{msec}$ ). The MR images for intraoperative navigation were obtained with patients placed in a Leksell frame and a 1.5-T magnet (GE Signa Excite). Both volumetric T1- and T2-weighted sequences were obtained at a slice thickness of $1 \mathrm{~mm}$.

\section{VIM Localization on Diffusion Tensor Imaging}

The methodology of DTI-based VIM identification has been described in detail previously. ${ }^{37}$ Briefly, we used StealthViz software (version 1, Medtronic Inc.) for coregistration of structural and diffusion tensor images and tensor calculation. We then identified the PT and ML, since these tracts form the lateral and posterior boundaries of the VIM nucleus, respectively. A VIM ROI was then created and placed equidistant ( $3 \mathrm{~mm}$ each) from the PT and ML, approximating the axial and sagittal dimensions of the human $\mathrm{VIM}^{20}$ (4 mm mediolateral, $3 \mathrm{~mm}$ anteroposterior, and $6 \mathrm{~mm}$ superoinferior). The structural connectivity of this VIM ROI was traced to the contralateral cerebellum and ipsilateral primary motor cortex. For intraoperative guidance, the individual tracts (PT, ML, and VIM fibers) were overlaid on structural T1-weighted images and exported to stereotactic planning software (Framelink, Medtronic Inc.). The resultant DICOM data set was then rigidly aligned to the preoperative frame-based T1weighted image used for intraoperative targeting.

\section{Intraoperative Recording and Testing}

The VIM was surgically targeted using the standard MER-guided approach. A typical microelectrode trajectory started $10 \mathrm{~mm}$ above the intended target and traversed from the anterolateral direction to the posteromedial direction. Each track used 2 microelectrodes $(25-\mu \mathrm{m}$ tip, $600 \mu \mathrm{m}$ apart, and 0.2-M $\Omega$ impedance at $1000 \mathrm{~Hz}$ ) loaded into a 2-channel cannula and driven forward by 2 independent manual microdrives. The amplified signals were band passed (10-3000 Hz) and simultaneously displayed on an oscilloscope and heard through an audio speaker output. The recordings were also fed to a digital interface (micro1401, Cambridge Electronic Design) for display and saved for offline analysis using Spike2 Neurological Capture (Cambridge Electronic Design). ${ }^{30}$ We identified tremor cells and kinesthetic cells and assessed tremor efficacy using clinical stimulations (100 milliamp, $100 \mathrm{~Hz}$ ) at $1-\mathrm{mm}$ increments. Using this setup, the estimated current spread is typically within $1 \mathrm{~mm}$ of the microelectrode tip. $^{51}$ The tremor efficacy was categorized into 4 categories based on a comparison of pre- and poststimulation clinical tremor scoring on a 4-point scale: no efficacy $(0 \%$ reduction or 0 points on the tremor scale), mild efficacy $(<$ $50 \%$ reduction or 1 point on the tremor scale), moderate efficacy ( $\geq 50 \%$ reduction or 2 points on the tremor scale), and tremor arrest $(100 \%$ reduction or $>2$ points on the tremor scale). The final electrode implantation was performed at a site with good tremor efficacy and acceptable side effect profile (no lemniscal and pyramidal side effects at clinically relevant stimulation thresholds). All recording data were stored on a central server for offline analysis.

\section{Electrophysiology Analysis}

Intraoperative recordings were analyzed offline using Spike2 software (version 7, Cambridge Electronic Design). We identified single-unit activity with a high signal-to-noise ratio (minimum 2:1) and applied a bandpass 
filter (200-3 kHz). Stable recordings (> 10 seconds) that were free from artifacts (noise, speech, motion, and clinical testing as measured by the accelerometer recordings) were isolated. Using the wave-mark function, we isolated spikes using template matching and principal component analysis. Single cells were segregated according to their relation to the VIM, similar to the methodology described previously for the subthalamic nucleus. ${ }^{2}$ The length of the VIM trajectory was normalized across subjects on a scale of 0 to 1 ( 1 corresponding to the top of the T-VIM and 0 corresponding to the bottom of the T-VIM). Thus, the cells ventral to the T-VIM had normalized values less than 0 (negative values), while the cells dorsal to the T-VIM had values greater than 1 .

Burst analysis was performed using the Kaneoke and Vitek methodology. ${ }^{24}$ Spike events were imported and processed using MATLAB (version 7, Mathworks). The discharge density histograms were then plotted with increasing densities from the left to the right. Burst index was calculated by dividing the mean interspike interval (ISI) by the modal ISI. Other parameters analyzed included the firing rate, mean ISI within the burst, and mean ISI outside of the burst. For the LFP analysis, recording segments (approximately 3 segments per $\mathrm{mm}$ ) were analyzed along the trajectory. LFP beta power was calculated similar to the methodology described elsewhere. ${ }^{6}$ Briefly, recordings were bandpass filtered in the beta frequency range $(13-30 \mathrm{~Hz})$ and the beta power of each recording segment was separately calculated by first performing a Fourier transform and then determining the area under the beta frequency peak. This beta power was then plotted against the normalized depth within the VIM as described above.

\section{Statistical Analysis}

Data were imported into SPSS (version 22, IBM Corp.) for statistical analysis. Continuous variables were compared using the t-test and ANOVA. Categorical variables were compared using the chi-square test; $p<0.05$ was considered statistically significant.

\section{Results \\ Demographics}

The mean age of this cohort was $71.7 \pm 5.9$ years, and the mean Clinical Rating Scale for Tremor (CRST) subscale B (specific motor tasks/function rating score) was $17.8 \pm 5.4$. Three patients had essential tremor and $3 \mathrm{had}$ tremor-dominant Parkinson's disease. In total, 9 microelectrode trajectories were performed. A typical trajectory is shown in Fig. 1.

\section{Distribution of Kinesthetic and Tremor Cells}

Overall, 20 kinesthetic and 26 tremor cells were identified (Fig. 2). In relation to the T-VIM, the kinesthetic cells were located mainly in the dorsal part (mean normalized
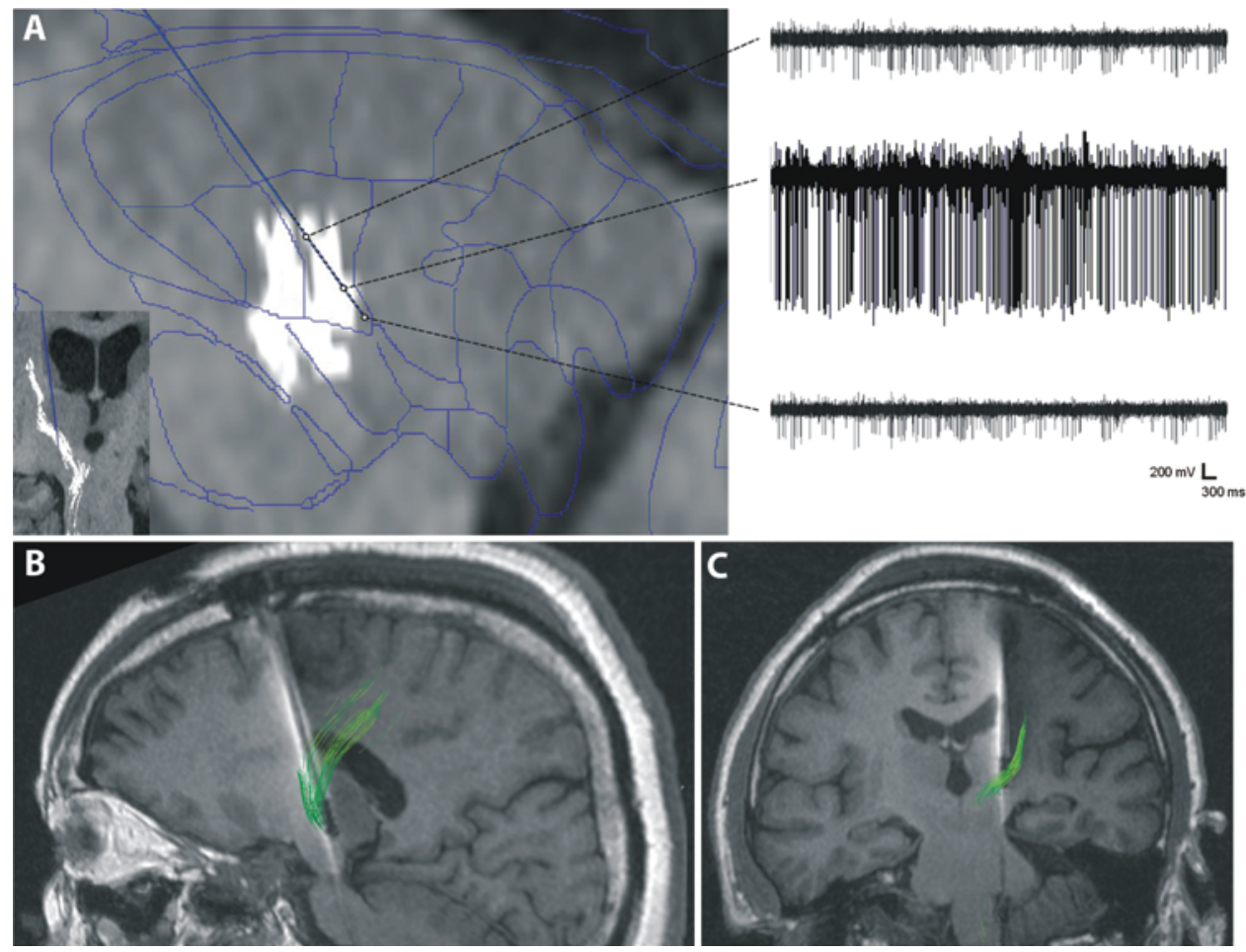

FIG. 1. A: Sagittal and coronal (inset) T1-weighted MRI projections with the T-VIM are shown in relation to the stereotactic trajectory. The Schaltenbrand and Wahren atlas is also overlaid to visualize the relationship between the T-VIM and the atlas-based VIM. Representative recordings from cells sampled within the T-VIM, and ventral to T-VIM are shown. B and C: The postoperative MR image is rigidly aligned with the preoperative tractography to visualize the final DBS lead in relation to the T-VIM in sagittal (B) and coronal (C) images. Overlay reprinted from Schaltenbrand G, Wahren W (eds): Atlas for Stereotaxy of the Human Brain, ed 2. Stuttgart: Thieme, 1977, plate 43 (LXXVIII) sagittal 12.0. Published with permission. Figure is available in color online only. 


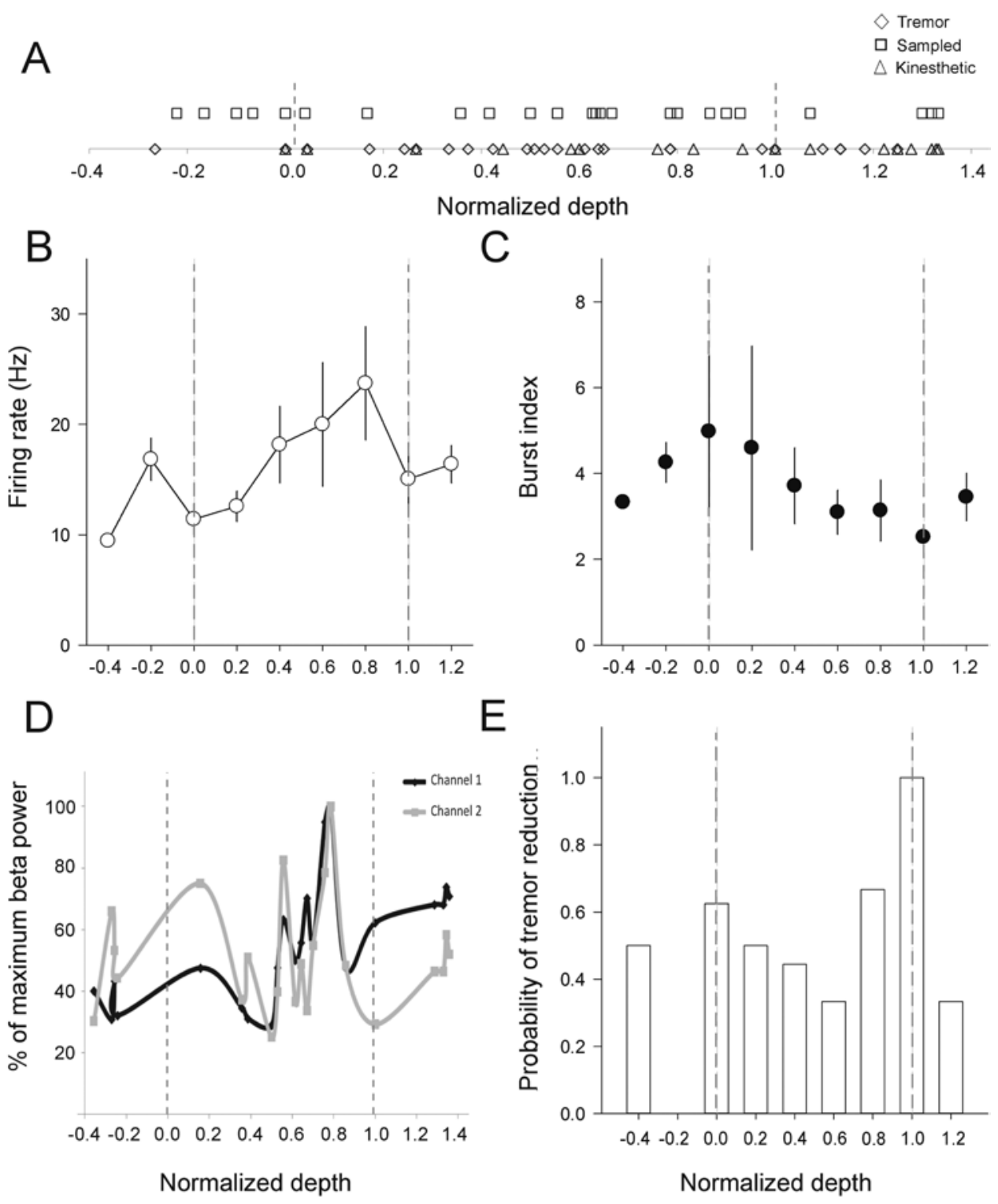

FIG. 2. A: The distribution of thalamic cells along the stereotactic trajectory in relation to the normalized T-VIM (1 corresponds to the dorsal border and 0 to the ventral T-VIM border). Among the 73 cells sampled from 6 patients ( 9 trajectories), we identified kinesthetic cells $(n=20)$ and tremor cells $(n=26)$. Twenty-seven cells meeting the inclusion and exclusion criteria were selected for further spike and burst analysis. B: The firing rate along the electrode trajectory in relation to the location with the T-VIM. Neurons within the dorsal T-VIM have a higher firing rate than those outside the T-VIM, although this relation is not statistically significant (2-tailed t-test, $p=0.2$ ). C: The burst index along the electrode trajectory in relation to the location with the T-VIM. In contrast to the firing rate, neurons in the ventral T-VIM have higher burst index (1-way ANOVA, $p<0.001)$. D: The area under the curve for beta oscillations $(13-30 \mathrm{~Hz})$ is plotted for 2 representative trajectories. There was a trend toward higher beta power in the dorsal T-VIM ( $R^{2}$ between beta power and normalized depth $\left.=0.35, p=0.08\right)$. E: The probability of tremor reduction in relation to the location of the T-VIM. Microelectrode stimulation within the T-VIM resulted in significant tremor reduction $(50 \% \pm 34.9 \%)$. Specifically, the most significant tremor reduction was observed in the dorsal T-VIM (64\% $\pm 19.5 \%)$ compared with $25 \% \pm 17.3 \%$ reduction immediately proximal to the T-VIM (2-sample t-test, $p=0.02)$.

depth $0.95 \pm 0.49)$ and the tremor cells in the ventral part (mean normalized depth $0.63 \pm 0.44 ; 2$-sample t-test, $\mathrm{p}=$ $0.03)$. The kinesthetic cells responded to movements of the shoulder ( 2 cells), elbow (14 cells), and wrist (5 cells). Increased firing rate was observed in response to joint movement in all but one instance, in which the thalamic cell was inhibited by elbow flexion.

\section{Spike and Burst Analysis}

We identified 27 thalamic cells that met the inclusion criteria for spike analysis. The location of these cells is illustrated in Fig. 2. Overall, 18 cells were localized within the T-VIM, 5 cells were dorsal to the T-VIM, and 4 cells were ventral to the T-VIM. The mean firing rate of cells within the T-VIM was $18.8 \pm 9.8 \mathrm{~Hz}$. There was a transi- 
tion in the firing rate as the electrode entered the T-VIM. The mean firing rate of thalamic cells located dorsal to the T-VIM was $15.2 \pm 4.4 \mathrm{~Hz}$ compared with $26.6 \pm 10.4 \mathrm{~Hz}$ for the cells within the first few millimeters of electrode entry into the T-VIM (2 sample t-test, $\mathrm{p}=0.2$ ). As shown in Fig. 2 we noticed a higher amplitude of action potential within the T-VIM, suggesting large neurons. Both the cells within and outside the T-VIM exhibited the typical irregular firing pattern with burst indices of $4.5 \pm 5.4$ and $3.8 \pm 0.8$, respectively. However, there was a significant association between burst index and depth within T-VIM (1-way ANOVA, $p<0.001$ ), with cells recorded toward the bottom of T-VIM tending to have a higher burst index.

\section{LFP Analysis}

Significant LFP beta power was identified within the T-VIM (area under the curve for $13-30 \mathrm{~Hz}=6.6 \pm 7.7$ ). There was a trend toward higher beta power in the dorsal T-VIM (Pearson's correlation coefficient $\left[R^{2}\right]$ between beta power and normalized depth $=0.35, \mathrm{p}=0.08$ ). A representative track from one patient is reconstructed for the area under the main spectral peak for the $13-$ to $30-\mathrm{Hz}$ frequency (Fig. 2).

\section{Tremor Efficacy}

Microelectrode stimulation within the T-VIM resulted in significant reduction in tremor $(50 \% \pm 34.9 \%$ corresponding to a 2-point difference in the tremor rating score). Although stimulation reduced tremor outside the TVIM, the magnitude of this reduction was smaller $(30 \% \pm$ $29.4 \%$ decrease in tremor score; 2 -sample t-test, $\mathrm{p}=0.08$ ). The most significant reduction in tremor was observed in the dorsal T-VIM $(64 \% \pm 19.5 \%$ reduction in dorsal TVIM vs $25 \% \pm 17.3 \%$ reduction immediately above the VIM, 2-sample t-test, $\mathrm{p}=0.02$ ).

\section{Clinical Outcomes}

The $\mathrm{x}, \mathrm{y}$, and $\mathrm{z}$ coordinates of the T-VIM and surgically identified VIM in relation to the posterior commissure were $14.3,7.2$, and 0.3 and $13,6.5$, and 0.5 , respectively.

Over the long term (follow-up $8.9 \pm 2.6$ months, range 5-11 months), the CRST subscale B improved by $56 \%$ (SD $11.9 \%$, range $41 \%-75 \%$ ). The CRST subscale B improvement on the operated side improved by $78 \%$ (SD 17.2\%, range 50\%-100\%).

\section{Discussion}

In this combined imaging and electrophysiology study, we established that the electrophysiological findings within the area of the thalamus defined by tractography or TVIM confirm the known MER characteristics of the VIM in patients with tremor.

At present, refractory essential tremor is most often surgically treated by targeting the VIM with radiofrequency lesioning ${ }^{39}$ or DBS, ${ }^{27}$ Gamma Knife lesioning, ${ }^{56}$ and more recently with MR-guided focused ultrasound lesioning. ${ }^{5,34}$ While the outcome of these treatments is crucially dependent on precise VIM localization, ${ }^{36}$ stereotactic VIM targeting relies on indirect methods because the structural MR images (both 1.5 and $3 \mathrm{~T}$ ) fail to visualize individual thalamic nuclei. ${ }^{9}, 18$ Indirect targeting relies on standard coordinates without accounting for the interindividual variability in thalamic structure and location. ${ }^{10,23,25}$ This may potentially result in heterogeneous outcomes after tremor surgery. ${ }^{5,16,41}$ Moreover, emerging noninvasive techniques ${ }^{15,34,56}$ preclude the confirmation with MER mapping, creating an immediate need for reliable, direct targeting of the VIM. Several techniques have previously been investigated, including gradient-filtered T1-weighted imaging, ${ }^{11} \mathrm{~T} 1$ and T2 dependence-weighted 3-T imaging, ${ }^{46}$ multiparametric ("virtual-dot-com imaging") 3-T imaging, ${ }^{55}$ optimized magnetization transfer mapping with 3-T imaging, ${ }^{17}$ susceptibility-enhanced T1-weighted $3 \mathrm{~T}$ imaging, ${ }^{54}$ and susceptibility-weighted 7-T imaging. ${ }^{1}$ However, so far, none of these have been translated into clinical application.

A dysfunction within the cerebellothalamocortical network has recently been implicated in tremor pathophysiology. $7,13,14,35,42,44,48$ Indeed, functional neuroimaging studies associate the successful modulation of this network with good surgical outcomes after VIM DBS ${ }^{26}$ and thalamotomy. ${ }^{50}$ In particular, the effective DBS contacts appear to lie close to the DRT. ${ }^{12,25}$ The emerging direct targeting methods for the VIM have also adopted this network-centered approach. Some studies have demarcated thalamic subregions based on their inherent diffusion characteristics ${ }^{47,49,57}$ or their connectivity with different cortical regions, ${ }^{8,45}$ and more recently have used probabilistic $\mathrm{c}^{22,23,28,40}$ and deterministic ${ }^{3,12,25,52,53}$ DTI algorithms to directly map the DRT. While novel and valuable, these approaches have not found a clinical application due to several limitations; for example, they are often computationally intensive, poorly integrated with stereotactic targeting platforms, or too imprecise for clinical application, where an accuracy of less than $1 \mathrm{~mm}$ is desired. ${ }^{43} \mathrm{We}$ recently described a tractography-based targeting method that identified the T-VIM according to the relative location of the surrounding PT and ML, which are easily visualized with DTI. ${ }^{37}$ Selecting a thalamic subregion of comparable size to the anatomical VIM, ${ }^{20}$ we confirmed the structural connectivity of the T-VIM with the cerebellum and motor cortex. Overall, we found this method to be accurate, reproducible, and useful for stereotactic VIM targeting. Notably, we found a good correlation between the coordinates of T-VIM and the final surgical VIM target, implying that the T-VIM is in the vicinity of the actual VIM.

In this investigation, we analyzed MER data to interrogate the electrophysiological properties of the T-VIM and thereby understand its relationship to the anatomical VIM. We found that the cells recorded within the T-VIM have firing rate and burst characteristics similar to those seen in the human VIM. ${ }^{29,31}$ In further concordance with the literature, we also identified kinesthetic cells $^{30,32}$ and tremor cells (with a typical oscillatory frequency of around $6 \mathrm{~Hz}$, and corresponding to tremor) ${ }^{21,33}$ all throughout the electrode tract often located above, within, and below the T-VIM. The LFP analysis also yielded results in line with other published reports, ${ }^{6}$ as we found significant beta oscillatory activity within the T-VIM. Finally, microelectrode stimulations confirmed that the zone of greatest tremor efficacy was co-localized 
with the T-VIM. There is a lack of clarity in the published imaging literature about whether DRT terminations truly represent the anatomical VIM or whether it instead represents other neighboring structures like thalamic nucleus ventralis oralis posterior, caudal zona incerta, and posterior subthalamic region..$^{2,38}$ Our findings in this combined imaging and electrophysiology study suggest that DRT terminations within the T-VIM do in fact represent the VIM subregion of the thalamus.

Several limitations of this study should be noted. First, we have used a single tensor tractography algorithm for delineating the T-VIM that has poor resolution for crossing fibers. However, since the VIM is a relay nucleus, ${ }^{19}$ the better resolution afforded by more advanced algorithms ${ }^{8,43}$ does not offer a significant advantage in visualizing the T-VIM. The algorithm used for this study was chosen due to its ease of tensor calculation, tract visualization, and integration with the stereotactic targeting platform. Another limitation was the small sample size of this study, which precluded us from describing either the somatotopy or tremor efficacy zones within the T-VIM.

\section{Conclusions}

The electrophysiological findings within the VIM defined by tractography, or T-VIM, correspond with the known MER characteristics of the VIM. In the future, long-term tremor outcomes associated with T-VIM targeting and their comparisons with conventional MER-guided methods are desirable.

\section{References}

1. Abosch A, Yacoub E, Ugurbil K, Harel N: An assessment of current brain targets for deep brain stimulation surgery with susceptibility-weighted imaging at 7 tesla. Neurosurgery 67:1745-1756, 2010

2. Alavi M, Dostrovsky JO, Hodaie M, Lozano AM, Hutchison WD: Spatial extent of $\beta$ oscillatory activity in and between the subthalamic nucleus and substantia nigra pars reticulata of Parkinson's disease patients. Exp Neurol 245:60-71, 2013

3. Anthofer J, Steib K, Fellner C, Lange M, Brawanski A, Schlaier J: The variability of atlas-based targets in relation to surrounding major fibre tracts in thalamic deep brain stimulation. Acta Neurochir (Wien) 156:1497-1504, 2014

4. Asanuma C, Thach WT, Jones EG: Distribution of cerebellar terminations and their relation to other afferent terminations in the ventral lateral thalamic region of the monkey. Brain Res 286:237-265, 1983

5. Barbe MT, Liebhart L, Runge M, Pauls KA, Wojtecki L, Schnitzler A, et al: Deep brain stimulation in the nucleus ventralis intermedius in patients with essential tremor: habituation of tremor suppression. J Neurol 258:434-439, 2011

6. Basha D, Dostrovsky JO, Lopez Rios AL, Hodaie M, Lozano AM, Hutchison WD: Beta oscillatory neurons in the motor thalamus of movement disorder and pain patients. Exp Neurol 261:782-790, 2014

7. Bastian AJ, Thach WT: Cerebellar outflow lesions: a comparison of movement deficits resulting from lesions at the levels of the cerebellum and thalamus. Ann Neurol 38:881-892, 1995

8. Behrens TEJ, Johansen-Berg H, Woolrich MW, Smith SM, Wheeler-Kingshott CAM, Boulby PA, et al: Non-invasive mapping of connections between human thalamus and cortex using diffusion imaging. Nat Neurosci 6:750-757, 2003

9. Benabid AL, Pollak P, Gervason C, Hoffmann D, Gao DM,
Hommel M, et al: Long-term suppression of tremor by chronic stimulation of the ventral intermediate thalamic nucleus. Lancet 337:403-406, 1991

10. Brierley JB, Beck E: The significance in human stereotactic brain surgery of individual variation in the diencephalon and globus pallidus. J Neurol Neurosurg Psychiatry 22:287298, 1959

11. Byne W, Buchsbaum MS, Kemether E, Hazlett EA, Shinwari A, Mitropoulou V, et al: Magnetic resonance imaging of the thalamic mediodorsal nucleus and pulvinar in schizophrenia and schizotypal personality disorder. Arch Gen Psychiatry 58:133-140, 2001

12. Coenen VA, Allert N, Paus S, Kronenbürger M, Urbach H, Mädler B: Modulation of the cerebello-thalamo-cortical network in thalamic deep brain stimulation for tremor: a diffusion tensor imaging study. Neurosurgery 75:657-670, 2014

13. Colebatch JG, Findley LJ, Frackowiak RS, Marsden CD, Brooks DJ: Preliminary report: activation of the cerebellum in essential tremor. Lancet 336:1028-1030, 1990

14. Deuschl G, Raethjen J, Lindemann M, Krack P: The pathophysiology of tremor. Muscle Nerve 24:716-735, 2001

15. Elias WJ, Huss D, Voss T, Loomba J, Khaled M, Zadicario E, et al: A pilot study of focused ultrasound thalamotomy for essential tremor. N Engl J Med 369:640-648, 2013

16. Favilla CG, Ullman D, Wagle Shukla A, Foote KD, Jacobson CE IV, Okun MS: Worsening essential tremor following deep brain stimulation: disease progression versus tolerance. Brain 135:1455-1462, 2012

17. Gringel T, Schulz-Schaeffer W, Elolf E, Frölich A, Dechent P, Helms G: Optimized high-resolution mapping of magnetization transfer (MT) at 3 Tesla for direct visualization of substructures of the human thalamus in clinically feasible measurement time. J Magn Reson Imaging 29:1285-1292, 2009

18. Hamani C, Dostrovsky JO, Lozano AM: The motor thalamus in neurosurgery. Neurosurgery 58:146-158, 2006

19. Hirai T, Jones EG: A new parcellation of the human thalamus on the basis of histochemical staining. Brain Res Brain Res Rev 14:1-34, 1989

20. Hirai T, Ohye C, Nagaseki Y, Matsumura M: Cytometric analysis of the thalamic ventralis intermedius nucleus in humans. J Neurophysiol 61:478-487, 1989

21. Hua SE, Lenz FA, Zirh TA, Reich SG, Dougherty PM: Thalamic neuronal activity correlated with essential tremor. J Neurol Neurosurg Psychiatry 64:273-276, 1998

22. Hyam JA, Owen SL, Kringelbach ML, Jenkinson N, Stein JF, Green AL, et al: Contrasting connectivity of the ventralis intermedius and ventralis oralis posterior nuclei of the motor thalamus demonstrated by probabilistic tractography. Neurosurgery 70:162-169, 2012

23. Johansen-Berg H, Behrens TE, Sillery E, Ciccarelli O, Thompson AJ, Smith SM, et al: Functional-anatomical validation and individual variation of diffusion tractographybased segmentation of the human thalamus. Cereb Cortex 15:31-39, 2005

24. Kaneoke Y, Vitek JL: Burst and oscillation as disparate neuronal properties. J Neurosci Methods 68:211-223, 1996

25. Kincses ZT, Szabó N, Valálik I, Kopniczky Z, Dézsi L, Klivényi P, et al: Target identification for stereotactic thalamotomy using diffusion tractography. PLoS One 7:e29969, 2012

26. Klein JC, Barbe MT, Seifried C, Baudrexel S, Runge M, Maarouf M, et al: The tremor network targeted by successful VIM deep brain stimulation in humans. Neurology 78:787795, 2012

27. Kumar R, Lozano AM, Sime E, Lang AE: Long-term followup of thalamic deep brain stimulation for essential and parkinsonian tremor. Neurology 61:1601-1604, 2003

28. Kwon HG, Hong JH, Hong CP, Lee DH, Ahn SH, Jang SH: 
Dentatorubrothalamic tract in human brain: diffusion tensor tractography study. Neuroradiology 53:787-791, 2011

29. Lee BH, Lee KH, Chung SS, Chang JW: Neurophysiological identification and characterization of thalamic neurons with single unit recording in essential tremor patients. Acta Neurochir Suppl 87:133-136, 2003

30. Lenz FA, Dostrovsky JO, Tasker RR, Yamashiro K, Kwan HC, Murphy JT: Single-unit analysis of the human ventral thalamic nuclear group: somatosensory responses. J Neurophysiol 59:299-316, 1988

31. Lenz FA, Jaeger CJ, Seike MS, Lin YC, Reich SG: Singleneuron analysis of human thalamus in patients with intention tremor and other clinical signs of cerebellar disease. J Neurophysiol 87:2084-2094, 2002

32. Lenz FA, Kwan HC, Dostrovsky JO, Tasker RR, Murphy JT, Lenz YE: Single unit analysis of the human ventral thalamic nuclear group. Activity correlated with movement. Brain 113:1795-1821, 1990

33. Lenz FA, Kwan HC, Martin RL, Tasker RR, Dostrovsky JO, Lenz YE: Single unit analysis of the human ventral thalamic nuclear group. Tremor-related activity in functionally identified cells. Brain 117:531-543, 1994

34. Lipsman N, Schwartz ML, Huang Y, Lee L, Sankar T, Chapman M, et al: MR-guided focused ultrasound thalamotomy for essential tremor: a proof-of-concept study. Lancet Neurol 12:462-468, 2013

35. Nicoletti G, Manners D, Novellino F, Condino F, Malucelli E, Barbiroli B, et al: Diffusion tensor MRI changes in cerebellar structures of patients with familial essential tremor. Neurology 74:988-994, 2010

36. Papavassiliou E, Rau G, Heath S, Abosch A, Barbaro NM, Larson PS, et al: Thalamic deep brain stimulation for essential tremor: relation of lead location to outcome. Neurosurgery 54:1120-1130, 2004

37. Sammartino F, Krishna V, King NKK, Lozano AM, Schwartz ML, Huang Y, et al: Tractography-based ventral intermediate nucleus targeting: novel methodology and intraoperative validation. Mov Disord [epub ahead of print], 2016

38. Schlaier J, Anthofer J, Steib K, Fellner C, Rothenfusser E, Brawanski A, et al: Deep brain stimulation for essential tremor: targeting the dentato-rubro-thalamic tract? Neuromodulation 18:105-112, 2015

39. Schuurman PR, Bosch DA, Bossuyt PM, Bonsel GJ, van Someren EJ, de Bie RM, et al: A comparison of continuous thalamic stimulation and thalamotomy for suppression of severe tremor. N Engl J Med 342:461-468, 2000

40. Sedrak M, Gorgulho A, Frew A, Behnke E, DeSalles A, Pouratian N: Diffusion tensor imaging and colored fractional anisotropy mapping of the ventralis intermedius nucleus of the thalamus. Neurosurgery 69:1124-1130, 2011

41. Shih LC, LaFaver K, Lim C, Papavassiliou E, Tarsy D: Loss of benefit in VIM thalamic deep brain stimulation (DBS) for essential tremor (ET): how prevalent is it? Parkinsonism Relat Disord 19:676-679, 2013

42. Shin DH, Han BS, Kim HS, Lee PH: Diffusion tensor imaging in patients with essential tremor. AJNR Am J Neuroradiol 29:151-153, 2008

43. Thomas C, Ye FQ, Irfanoglu MO, Modi P, Saleem KS, Leopold DA, et al: Anatomical accuracy of brain connections derived from diffusion MRI tractography is inherently limited. Proc Natl Acad Sci U S A 111:16574-16579, 2014

44. Timmermann L, Gross J, Dirks M, Volkmann J, Freund HJ, Schnitzler A: The cerebral oscillatory network of parkinsonian resting tremor. Brain 126:199-212, 2003

45. Traynor C, Heckemann RA, Hammers A, O'Muircheartaigh J, Crum WR, Barker GJ, et al: Reproducibility of thalamic segmentation based on probabilistic tractography. Neuroimage 52:69-85, 2010
46. Traynor CR, Barker GJ, Crum WR, Williams SC, Richardson MP: Segmentation of the thalamus in MRI based on T1 and T2. Neuroimage 56:939-950, 2011

47. Unrath A, Klose U, Grodd W, Ludolph AC, Kassubek J: Directional colour encoding of the human thalamus by diffusion tensor imaging. Neurosci Lett 434:322-327, 2008

48. Velasco F, Velasco M, Romo R, Maldonado H: Production and suppression of tremor by mesencephalic tegmental lesions in monkeys. Exp Neurol 64:516-527, 1979

49. Wiegell MR, Tuch DS, Larsson HB, Wedeen VJ: Automatic segmentation of thalamic nuclei from diffusion tensor magnetic resonance imaging. Neuroimage 19:391-401, 2003

50. Wintermark M, Huss DS, Shah BB, Tustison N, Druzgal TJ, Kassell N, et al: Thalamic connectivity in patients with essential tremor treated with MR imaging-guided focused ultrasound: in vivo fiber tracking by using diffusion-tensor MR imaging. Radiology 272:202-209, 2014

51. Wu YR, Levy R, Ashby P, Tasker RR, Dostrovsky JO: Does stimulation of the GPi control dyskinesia by activating inhibitory axons? Mov Disord 16:208-216, 2001

52. Yamada K, Akazawa K, Yuen S, Goto M, Matsushima S, Takahata A, et al: MR imaging of ventral thalamic nuclei. AJNR Am J Neuroradiol 31:732-735, 2010

53. Yamada K, Nagakane Y, Yoshikawa K, Kizu O, Ito H, Kubota T, et al: Somatotopic organization of thalamocortical projection fibers as assessed with MR tractography. Radiology 242:840-845, 2007

54. Young GS, Feng F, Shen H, Chen NK: Susceptibilityenhanced 3-Tesla T1-weighted spoiled gradient echo of the midbrain nuclei for guidance of deep brain stimulation implantation. Neurosurgery 65:809-815, 2009

55. Yovel Y, Assaf Y: Virtual definition of neuronal tissue by cluster analysis of multi-parametric imaging (virtual-dot-com imaging). Neuroimage 35:58-69, 2007

56. Zesiewicz TA, Elble R, Louis ED, Hauser RA, Sullivan KL, Dewey RB Jr, et al: Practice parameter: therapies for essential tremor: report of the Quality Standards Subcommittee of the American Academy of Neurology. Neurology 64:20082020, 2005

57. Ziyan U, Tuch D, Westin CF: Segmentation of thalamic nuclei from DTI using spectral clustering. Med Image Comput Comput Assist Interv 9:807-814, 2006

\section{Disclosures}

The authors report no conflict of interest concerning the materials or methods used in this study or the findings specified in this paper.

\section{Author Contributions}

Conception and design: Krishna, King. Acquisition of data: Krishna, King, Basha, Elias, Sammartino. Analysis and interpretation of data: Krishna, King, Basha, Elias, Hutchison. Drafting the article: Krishna, Basha. Critically revising the article: Sammartino, Hodaie, Lozano, Hutchison. Reviewed submitted version of manuscript: all authors. Approved the final version of the manuscript on behalf of all authors: Krishna. Statistical analysis: Krishna, King, Hutchison.

\section{Correspondence}

Vibhor Krishna, Center for Neuromodulation, Department of Neurosurgery, The Ohio State University, 480 Medical Center Dr., \#S1019, Columbus, OH 43210. email: vibhor.krishna@ osumc.edu. 